\title{
Trajetória docente em educação física: percursos formativos e profissionais
}

\author{
Alexandra FOLLE* \\ Juarez Vieira do NASCIMENTO*
}

${ }^{*}$ Centro de Desportos e Saúde, Universidade Federal de Santa Catarina.

\section{Resumo}

0 presente estudo teve como objetivo analisar a trajetória docente em Educação Física. Os percursos formativos e profissionais de quatro professores de Educação Física, com mais de 25 anos de intervenção profissional em escolas estaduais da cidade de Florianópolis foram investigados. Para analisar a trajetória docente foram utilizadas três fontes de coletas de informações: a) entrevistas semi-estruturadas com os professores de Educação Física; b) entrevistas semi-estruturadas com três colegas de trabalho; c) análise documental. A técnica da análise de conteúdo foi utilizada na análise das informações. Os resultados revelaram que os professores, ao mesmo tempo em que tiveram experiências positivas diversificadas durante suas formações iniciais, vivenciaram experiências negativas muito similares, destacando-se a distância entre suas experiências formativas e a realidade das escolas públicas. Como estratégia de continuidade do percurso formativo, os docentes realizaram cursos de pós-graduação em nível de especialização e de capacitação profissional. A entrada na carreira possibilitou sentimentos tanto de sobrevivência quanto de descoberta, sobressaindo-se o choque com a realidade. No decorrer de seus percursos profissionais, assumiram cargos comissionados e de confiança nas escolas em que atuavam. 0 desinvestimento amargo predomina no percurso profissional de apenas um professor, enquanto os demais demonstram aguardar a aposentadoria de forma mais serena. Como expectativas relacionadas à aposentadoria, pretendem desenvolver atividades profissionais diversificadas, não retornando à docência escolar.

UnITERMos: Formação profissional; Entrada na carreira; Ciclos de vida docente; Aposentadoria.

\section{Introdução}

A trajetória profissional de professores, tanto da educação básica quanto da educação superior, vem sendo analisada por alguns investigadores por meio de fases ou ciclos de vida docente (BARONE, BERLINger, Blanchard, Casanova \& McGowan, 1996; Burke, Christensen, Fessler, McDonnell \& Price, 1987; Feiman-Nemser, 1982; GonÇAlves, 2000; Huberman, 2000; NASCIMENTO \& GRAÇA, 1998; RoDrigues, 1987; Stefy, Wolfe, Pasch \& Enz, 2000; Stroot, 1996). As classificaçóes propostas para o percurso profissional dos professores englobam desde os estudantes em situações de estágios ou os docentes em início da carreira até os que se apresentam numa fase de desinvestimento ou que estão aposentados.

A última fase dos ciclos de vida profissional apresentada por alguns autores (BURKE et al., 1987; Gonçalves, 2000; Huberman, 2000; Nascimento
\& GraçA, 1998; Stefy et al., 2000) pode ser caracterizada como um momento de estabilização, compreendendo uma fase de maturidade e de questionamentos (NASCIMENTO \& GRAÇA, 1998). Um período de renovação do interesse e desencanto, ou seja, a divergência entre o entusiasmo, o desejo de aprender coisas novas e o cansaço, a saturação, a impaciência pela aposentadoria (GONÇALVES, 2000).

O sentimento de sucesso nesse momento do percurso profissional corresponde a uma fase de desinvestimento sereno, enquanto a sensação de desespero, seguida de uma estagnação no plano profissional, conduz a uma fase de desinvestimento amargo (Huberman, 2000).

A fase de professor emérito marca a permanência do professor aposentado na Educação, mantendo assim seu compromisso com a profissão e prolongando 
sua trajetória (STEFY et al., 2000). Além disso, a fase de saída da carreira representa o momento em que o professor deixa seu trabalho após refletir mais intensamente sobre o tempo em que continuou ativo após a aposentadoria (BURKE et al., 1987).

$\mathrm{Na}$ literatura consultada a respeito da temática da trajetória docente, constata-se uma lacuna em termos de investigações empíricas com professores no final de seus percursos profissionais ou aposentados. Contudo, destaca-se que alguns investigadores têm contribuído para sanar essa incipiência na produção científica da área, na tentativa de elucidar melhor como ocorre o processo de desvinculação com o ambiente de trabalho, bem como são analisadas as experiências profissionais vividas ao longo dos anos de docência (BEN-Peretz, 2000; BetTi \& Mizukami, 1997; BragançA, 2004; Chinelli \& Junqueira, 1998; Hopf, 2002; Hopf \& Canfield, 2001; Junges, 2006; Veiga, Moreira, Souza, Borges, Resende \& Pinheiro, 2007).

Nesse contexto, o presente estudo teve como objetivo analisar a trajetória docente em Educação Física. Para tanto, foram investigados os percursos formativos (formação inicial e continuada) e profissionais (entrada na carreira, desenvolvimento profissional, cargos assumidos, desinvestimento profissional e expectativas em torno da aposentadoria) de quatro professores de Educação Física com mais de 25 anos de intervenção profissional.

\section{Métodos}

A presente investigação se caracteriza como estudo de casos de histórias de vida, com abordagem qualitativa das informações. A produção de conhecimentos relacionados às histórias de vida engloba tanto relatos de uma vida quanto narraçóes parciais de determinadas etapas ou momentos vivenciados (QUEIROZ, 1988). De acordo com JunGES (2006), as histórias de vida de professores podem abordar três percursos: percurso pessoal (elementos da infância, da juventude e da constituição familiar do professor); percurso formativo (escolarização básica, formação acadêmica e extra-acadêmica); percurso profissional (início e desenvolvimento da carreira profissional). No caso específico dessa pesquisa, investigaram-se na trajetória docente tanto aspectos do percurso formativo quanto aspectos do percurso profissional de professores de Educação Física.

A maioria dos estudos qualitativos é conduzida com amostras pequenas, tendo como objetivo "captar a interpretação que determinada pessoa faz da sua própria vida" (Bogdan \& BiKLEN, 1994, p.17). Deste modo, o estudo de caso, segundo GIL (2002), destacase como uma modalidade de pesquisa, que consiste no estudo profundo e exaustivo de um ou poucos objetos, permitindo seu amplo e detalhado conhecimento.

A investigação delimitou-se por analisar as trajetórias docentes de quatro professores de Educação Física do magistério público estadual da cidade de Florianópolis (SC), levando-se em consideração os seguintes critérios para inclusão e exclusão dos participantes:

a) Critérios de inclusão: ser professor de Educação Física efetivo no magistério público estadual; ter mais de 25 anos de intervenção profissional no magistério público estadual; atuar em sala de aula; b) Critérios de exclusão: estar aposentado; exercer cargos administrativos na escola ou na Secretaria Estadual de Educação; estar afastado da escola por qualquer tipo de licença.

Para analisar a trajetória docente dos professores de Educação Física no magistério público estadual foram utilizadas três fontes de coletas de informações: a) entrevistas semi-estruturadas com os professores de Educação Física; b) entrevistas semiestruturadas com três colegas de trabalho (um representante da esfera administrativa, um representante da esfera pedagógica e um representante do corpo docente); c) análise documental ("Transcriçôes dos Assentamentos Funcionais e Cadastrais").

A triangulação das informações, contidas nas entrevistas e na análise dos documentos, buscou um maior aprofundamento das trajetórias docentes analisadas. Para um entendimento mais fiel das informaçōes obtidas nas investigações qualitativas, TRIVIÑos (1987) destaca a necessidade de realizar entrevistas com pessoas vinculadas ao sujeito principal do estudo, bem como revisar documentos e obras. Neste sentido, visando proporcionar maior confiabilidade às informaçôes e maior aprofundamento ao estudo do problema abordado foram realizadas entrevistas complementares, para reforçar ou contrapor as informações levantadas junto aos professores de Educação Física, com três colegas de trabalho atuantes nas mesmas escolas dos entrevistados. Para tanto, os professores investigados indicaram um representante de cada uma das esferas que pudessem contribuir com informações sobre sua trajetória docente. 
O presente estudo foi aprovado pelo Comitê de Ética em Pesquisa com Seres Humanos da Universidade Federal de Santa Catarina (029/08). Após a sua aprovação, foi realizado o primeiro contato por telefone com as secretarias das escolas em que os professores com mais de 25 anos de intervenção profissional atuavam (informação disponibilizada pelo setor de Recursos Humanos da Gerência de Educação), para levantar dados necessários para inclusão e exclusão dos professores no estudo. A seleção final dos professores, a partir dos critérios estabelecidos, foi realizada em contato pessoal para explicar os objetivos e os procedimentos do estudo, além da solicitação de assinatura do Termo de Consentimento Livre e Esclarecido.

Inicialmente, foram entrevistados os professores de Educação Física, e, em seguida, os colegas de trabalho indicados pelos investigados, de acordo com a disponibilidade de cada um. Todas as entrevistas foram realizadas individualmente, gravadas, transcritas na íntegra para facilitar o processo de análise dos dados e enviados aos professores e colegas de trabalho (para alterarem e/ou confirmarem as informações contidas na transcrição), como processo de validação de seu conteúdo.

As transcrições dos assentamentos funcionais e cadastrais dos professores foram fornecidas pelo setor de Recursos Humanos da Gerência de Educação da Secretaria de Estado do Desenvolvimento
Regional da Grande Florianópolis, as quais possibilitaram o levantamento de dados oficiais (nomeaçōes, ascensões, admissões, progressos, afastamentos, ...) da trajetória dos professores no magistério público estadual de Santa Catarina.

As informaçōes foram analisadas por meio da técnica de análise de conteúdo. A análise de conteúdo, segundo BARDIN (1977), é um conjunto de técnicas organizado por meio das seguintes fases: pré-análise (organização dos documentos); exploração do material (administração sistemática das decisōes tomadas); e, por fim, o tratamento dos resultados obtidos e sua interpretação (os resultados são tratados de maneira a serem significativos e válidos). Dessa forma, a análise por meio da técnica por categorias funciona por operaçôes de desmembramento do texto em unidades, em categorias e segundo reagrupamentos analógicos.

Além do emprego de múltiplas fontes de informação (YIN, 1995), os procedimentos de validade descritiva e interpretativa das informaçóes (Molina Neto \& Trivinos, 1999) foram adotados para assegurar a credibilidade do estudo. No entanto, as limitações das generalizaçóes do estudo podem ser minimizadas com o emprego do princípio de transferibilidade (Alves-Mazzotti \& Gewandsznajder, 1998), no sentido de que os resultados do estudo possam somente ser transferidos para contextos similares ou para o mesmo contexto em outras épocas.

\section{Resultados}

\section{Professor A: a intervenção no magistério público paralela ao ensino particular}

A trajetória docente do professor A no magistério estadual esteve, desde os primeiros anos de intervenção profissional, conciliada com o ensino privado. A expectativa profissional desse docente era trabalhar no ensino público e particular, conciliando, se possível, os dois locais de intervenção. Isto pode ser constatado em seu relato: “[...] por uma sorte, uma situação boa que aconteceu comigo até hoje milito nestas duas áreas, tanto no estado quanto no particular" (Professor A).

$\mathrm{O}$ percurso formativo desse professor iniciou-se ainda no ensino médio, quando optou pela realização do curso profissionalizante em Educação Física, ingressando em seguida no curso de licenciatura da área. Como aspectos positivos de sua formação inicial universitária, realizada em Instituição de Ensino Superior pública, ele destaca o fato do curso ser recente dentro da Universidade e contar naquele momento com professores qualificados. Nesse caso, a troca de experiências profissionais com aqueles docentes foi importante e contribuiu com sua intervenção profissional posterior.

No entanto, como fator negativo de seu percurso formativo, aponta o déficit na relação entre teoria e prática, a distância entre as experiências vividas na Universidade e a realidade das escolas, principalmente os estágios curriculares que eram realizados em locais muito diferentes da maioria das escolas públicas. Além disso, assinala um déficit no papel da Universidade no processo de indução profissional dos docentes por ela formados, tanto em termos de respaldo dentro das Secretarias de Educação quanto de defesa do trabalho docente (remuneração e reivindicaçōes de classe).

[...] locais que não eram a realidade que $90 \%$ da minha turma, que os alunos que estavam se formando iriam encontrar mais adiante, enquanto profissionais. Então a gente fazia um estágio maravilhoso 
[...], mas quando saía dali à realidade era outra. Isso

ficou muito defasado no nosso curso (Professor A).

$\mathrm{Na}$ continuidade de seu percurso formativo, logo após o término do curso de graduação, o docente realizou um curso técnico na área esportiva e somente em 1992 concluiu seu curso de especialização, buscando ampliar seus conhecimentos e avançar no plano de cargos e salários do magistério estadual.

A importância atribuída à formação continuada por esse professor contempla, além da troca de experiências com os professores do curso de especialização, a participação em eventos como seminários, simpósios, conferências e congressos, reconhecendo a necessidade de os professores buscarem constantemente novos subsídios para sua atuação prática. Todavia, o docente faz críticas à ausência de auxílio da Secretaria de Educação na formação continuada dos professores, o que dificulta um envolvimento mais efetivo nos programas de capacitação, devido principalmente às dificuldades financeiras pessoais para dar continuidade ao percurso formativo.

No início de seu percurso profissional, o professor A trabalhou como professor admitido em caráter temporário (ACT) durante um ano, e em seu segundo ano de atuação prestou concurso e se efetivou no magistério público estadual de Santa Catarina (1981). Nessa perspectiva, o professor enfatiza o fato de atuar há 27 anos na sua escola atual, ou seja, desde sua efetivação, bem como se orgulha por ter ingressado em uma escola particular naquele momento e por permanecer atuando até hoje.

No início da docência, caracterizado pela passagem de estudante a professor, o educador A demonstra que vivenciou fortemente o sentimento de sobrevivência na profissão. $O$ único aspecto de descoberta por ele relatado refere-se ao bom trabalho realizado em conjunto com os pares no desenvolvimento das aulas.

A sensação de sobrevivência foi representada pelo choque com a realidade, principalmente pelas facilidades que o docente tinha enquanto estudante e pelas dificuldades que encontrou enquanto profissional. Além disso, em muitos momentos sentiu-se vigiado e cobrado, demonstrando uma das características dessa fase do ciclo de vida docente: a preocupação consigo próprio vivenciada pelos professores iniciantes.

Contudo, a maior dificuldade dessa etapa narrada pelo professor se refere às péssimas condiçōes para o desenvolvimento do trabalho pedagógico na escola. Naquele período, o docente teve de adaptar seu espaço de trabalho, contando com a ajuda de pais e alunos, apesar de sofrer algumas repressóes por solicitar aos estudantes que o ajudassem.
Uma das dificuldades seriíssimas que eu tive foi quando cheguei à escola, não tinha quadra, me deram uma enxada na mão: 'está ali'. Eu reuni os alunos, pai de alunos e fomos capinar para fazer uma quadra e quase fui processado porque teve um pai que reclamou que eu botei o filho dele para capinar [...], inclusive foram lá dois pais e me ajudaram (Professor A).

No decorrer de seu percurso profissional, em uma fase de diversificação, o professor A assumiu cargo comissionado durante um ano. De acordo com a transcrição dos assentamentos funcionais e cadastrais, entre o sétimo e o oitavo ano de intervenção profissional (1986 a 1987), ele se afastou da sala de aula para assumir a função de diretor de escola. Experiência apenas citada pelo professor como marcante em sua trajetória docente, sobre a qual ele não disponibilizou muitas informaçôes.

No momento atual, o professor demonstra um sentimento muito forte por largar o ensino, alegando que esse desejo advém do fato de não sentir mais prazer em exercer sua profissão e apresentando traços marcantes, tanto de uma fase de questionamento quanto de uma fase de desinvestimento amargo do ensino. $\mathrm{O}$ único sentimento de desinvestimento sereno relatado pelo professor se remete as lembranças positivas do início do percurso profissional, recordações de colegas e alunos que marcaram significativamente aquele período e que deixarão saudades, saudades de um "tempo bom".

Tais lembranças são destacadas pela orientadora educacional de sua escola, a qual afirma que: "muitas vezes eu já vi ex-alunos que ele encontra e que vêm demonstrar carinho [...]. Enfim, é todo um reconhecimento, de um vínculo que ficou [...]. Eles pedem para ver ele, abraçar e conversar. Ele realmente se sente realizado [...]" (Orientadora educacional A).

De modo contrário, os aspectos de desinvestimento amargo sentidos pelo professor se relacionam a um afastamento causado por angústias e descontentamento com a profissão, resultantes do desinteresse dos alunos pelas aulas de Educação Física e do descaso do Governo pela Educação. Além disso, o professor se descreve como um docente desgostoso com a docência, devido à sobrecarga de trabalho neste momento final da carreira no magistério estadual. O sentimento de descontentamento do docente pode ser visualizado no relato abaixo:

Esse momento atual é muito triste, muito triste para mim. Esses dias eu cheguei em casa tão angustiado [...]. Comecei a refletir, refleti e comecei a chorar. Foi uma coisa assim que me entristeceu [...], hoje eu não estou mais conseguindo ter 
alegria, estou 'morrendo aos poucos' dentro da escola. (...) alguma coisa que tinha até certo brilho e que está se ofuscando [...] (Professor A).

$\mathrm{O}$ ressentimento em relação à docência causado por decepçôes ao longo da trajetória docente é percebido pelos colegas de trabalho. Para eles o fato do professor A ser comprometido com a sua profissão e estar enfrentado problemas com as péssimas condições de trabalho, com as políticas educacionais e, principalmente com o desinteresse dos alunos pelas aulas de Educação Física, leva-o a apresentar-se atualmente desestimulado, desanimado e cansado, e também angustiado por não conseguir realizar o seu trabalho.

[...] pessoa apaixonada pelo que faz, mas também bastante decepcionada com as condições de trabalho, com a situação dele, do material precário, das condiçôes da quadra. [...] ele não deixa de ser um profissional que ama o que faz, que briga pelo o que ele gosta. [...], mas ao mesmo tempo está angustiado com as coisas que ele não consegue realizar [...] (Orientadora educacional A).

Nessa perspectiva, a aposentadoria surge na vida do professor A como uma possibilidade de fugir das angústias e das incertezas do magistério. A respeito das expectativas de reinserção no mercado de trabalho após a aposentadoria, o professor demonstra interesse em realizar um curso em área de seu interesse e trabalhar em uma clínica de reabilitação cardíaca, expressando fortemente o desejo de se afastar da docência escolar.

Eu só quero enfatizar que com ensino, aulas de Educação Física em colégio não! Chega! Acho que já foi o meu limite, o que eu fiz, fiz, o que não fiz, desculpa, passou, mas com Educação Física, com aluno não! Eu lidar com aluno de novo não! Não! Com isso não (Professor A).

\section{Professor B: o desenvolvimento da docência marcado pelas experiências paralelas na arbitragem}

A trajetória docente no magistério público estadual do professor B sempre esteve conciliada e motivada pelas experiências paralelas que ele teve na arbitragem de competições estaduais, nacionais e internacionais, as quais serviram de suporte ao longo de sua intervenção profissional no contexto escolar.

A formação inicial do professor $\mathrm{B}$, realizada em instituição particular, teve como ponto positivo a participação nas disciplinas cursadas, as quais contribuíram posteriormente no dia-a-dia de sua atuação, bem como o estágio curricular, que lhe possibilitou um contato direto com escolas carentes, realidade na qual veio a atuar durante toda sua trajetória no magistério estadual de Santa Catarina. O estágio foi retratado pelo professor como um momento muito importante de seu percurso formativo, no qual contou com o apoio da direção e dos professores da escola, além de ter em suas turmas alunos dedicados e entusiasmados em participar das aulas.

O professor B se formou em 1974 e concluiu o curso de especialização em Voleibol em 1975, também em instituição privada do Estado de São Paulo, vindo para Santa Catarina em 1976, porque naquela época seu Estado natal estava saturado de professores da área e, ao contrário, não havia turmas de Educação Física formadas em Santa Catarina. Em sua narrativa, declara que ele foi um dos "pioneiros, tanto para o esporte [...] quanto para desenvolver atividades de Educação Física no estado" (Professor B). Todavia, é importante ressaltar que o curso de especialização realizado pelo professor B não lhe serviu como possibilidade de acesso nos planos de cargos e salários do magistério estadual. Nesse caso, visualiza-se em sua transcrição funcional que ele ainda se encontra no último nível (nove) e na última letra $(G)$ de professor licenciado.

Como complementação ao seu percurso formativo, o professor participou de vários cursos de aperfeiçoamento (congressos, simpósios, palestras), em sua maioria por conta própria, afirmando que recebeu pouco auxílio da Secretaria Estadual de Educação, principalmente nos últimos 10 anos. Todavia, orgulha-se por ser convidado por pessoas conhecidas para ministrar cursos referentes a regras esportivas para professores de Educação Física e por compartilhar com seus pares o que ele aprendeu nesses anos de arbitragem e de docência escolar.

A constatação de que a Secretaria tem auxiliado pouco o profissional da Educação Física em suas capacitações e de que ministrar cursos na área de arbitragem para outros professores de Educação Física é uma realização profissional para o professor $\mathrm{B}$ é ressaltada pela sua colega do corpo docente.

No início do seu percurso profissional, o professor $\mathrm{B}$ atuou três anos como ACT, e no final do terceiro ano passou no concurso para o magistério público estadual, assumindo como professor efetivo no começo do quarto ano de intervenção profissional (1978). Além disso, tornou-se árbitro estadual e nacional, atividade profissional simultânea ao magistério estadual desde aquela época e que perdura até o momento atual. Para o docente foi muito importante conciliar essas atividades no decorrer de sua trajetória profissional, pois segundo ele "a arbitragem é uma parte gostosa, que eu sempre quis na vida e que eu escolhi para essa vida" (Professor B). 
O professor enfatiza que, no processo de transição de estudante a professor, vivenciou alguns sentimentos de sobrevivência, principalmente o choque com o real e a distância entre seus ideais e a realidade cotidiana da escola, "[...] quando você se forma, você quer aplicar tudo aquilo que você teve de conhecimento e na realidade não é nada daquilo [...], você tem que se adaptar ao meio que você está" (Professor B).

No entanto, ao narrar suas experiências nos primeiros contatos com a atividade docente, demonstra que ela também foi marcada pelo entusiasmo da descoberta, lembrando que "[...] nos primeiros anos era tudo novidade [...]”, principalmente o intercâmbio esportivo entre as escolas que ocorria naquela época e o grupo de fanfarra que estava sendo formado na escola, ao qual ele deu continuidade. Para o professor B, trabalhar com o grupo de fanfarra foi um trabalho marcante e gratificante realizado dentro e fora da escola.

Participamos de desfile de sete de setembro e

a maioria das escolas que não tinha fanfarra naquela época convidava a gente para tocar para eles, foi uma coisa marcante, um trabalho que surtiu efeito, que deu resultado e que foi muito gratificante (Professor B).

No decorrer do percurso profissional, o professor $\mathrm{B}$ desenvolveu suas ações docentes em cinco escolas, atuando há 31 anos na escola atual e assumindo função de confiança como diretor de escola nos períodos de 1993 a 1995 e de 1999 a 2003. Além disso, foi árbitro internacional de 1990 a 2007 e se afastou da escola em 2003 para coordenar um projeto social.

Assumir a direção foi um trabalho muito marcante, no qual ele pôde desenvolver vários projetos sociais dentro da escola e em parceria com outras instituições. Para o docente é fundamental que todo professor tenha a oportunidade de assumir essa responsabilidade durante sua trajetória, para que o educador possa sentir "[...] o que é uma escola em um todo, não só dentro de uma sala de aula, mas em um todo [...] que envolve a parte docente, a parte discente, a comunidade [...]".

Observa-se que na fase de diversificação de seu desenvolvimento profissional o docente buscou alternar suas atividades profissionais, buscando cargos mais elevados (arbitragem internacional, direção de escola, coordenação de projeto social) eque lhe possibilitassem outras responsabilidades, além das que possuía em sala de aula no contato com os alunos. Além disso, constata-se que seu trabalho sempre esteve fortemente vinculado às questóes sociais, tanto no ambiente escolar quanto fora dele.

O professor B já possui 32 anos de intervenção profissional, porém sua trajetória no magistério público estadual está sendo prolongada devido ao tempo que ele passou fora da sala de aula. Na compreensão de seus colegas de trabalho, ele é muito comprometido e realizado com o ensino, vivendo a docência com dedicação e emoção, mas que no momento atual demonstra ter criado expectativas em relação à aposentadoria em função das mudanças constantes na legislação.

Na verdade eu acho que ele está ansioso para que chegue a aposentadoria, eu acho que talvez seja por causa desse processo que a cada momento vai mudando a legislação, já era para ele ter se aposentado há algum tempo [...] (Orientadora educacional B).

$\mathrm{Na}$ opinião do professor $\mathrm{B}$, nesse estágio atual de sua trajetória, ele espera a aposentadoria por meio de um desinvestimento sereno, afastando-se progressivamente do ambiente escolar para se dedicar a outras atividades e preparando-se emocionalmente e intelectualmente para abandonar a docência, pois, como ele destaca: "[...] é a mesma coisa que você cortar uma etapa de sua vida [...]”. Dessa forma, sairá com a certeza de que valeu a pena e que nunca será esquecido, ficando apenas a sensação de que poderia ter feito mais na Educação se não fossem as condiçōes oferecidas. $\mathrm{Na}$ declaração de sua colega, pode-se confirmar que:

[...] ele se dedicou, deu tudo o que podia [...].

Ele foi e é um bom profissional, o qual sairá com a certeza de que fez o melhor que podia [...]. Foi uma vida de trabalho com muitos frutos [...]. Alguém que irá sair e deixar muitas recordações, tanto para os alunos quanto para quem trabalhou com ele (Colega o corpo docente B).

A “aposentadoria não representada nada” para o professor B, pois ele acredita que continuará trabalhando em outras atividades, haja vista o salário não the possibilitar condições financeiras apropriadas para sua sustentação e da sua família. Dentre as atividades de interesse do professor, após o abandono da docência, estão o trabalho que ele vem desenvolvendo nos últimos anos como coordenador de árbitros e os planos futuros de trabalhar com culinária, abrindo um barzinho ou um restaurante. Em sua entrevista, a colega do corpo docente confirma a intenção demonstrada pelo docente em dar continuidade ao trabalho realizado na arbitragem após a aposentadoria e a vontade de não retornar para a docência em sala de aula.

\section{Professora C: a trajetória docente em Educação Física marcada pelo trabalho administrativo}

A trajetória docente da professora $\mathrm{C}$ no magistério estadual de Santa Catarina foi fortemente marcada pelo interesse e pela realização no trabalho desenvolvido nas 
secretarias das escolas em que atuou, declarando que ela "[...] gostava de fazer a papelada do professor, do administrativo, daquela burocracia toda” (Professora C).

O percurso formativo na área da Educação Física da educadora $C$ teve seu início durante a escolarização básica, no curso profissionalizante em Educação Física, sendo a partir das experiências vivenciadas nessa etapa que resolveu dar continuidade aos estudos na área. Durante o curso de graduação, realizado em Instituição de Ensino Superior pública, a docente relata que vivenciou experiências positivas nas disciplinas que envolviam atividades rítmicas e esportivas, ressaltando que gostava de participar também dos jogos e atividades que tinham entre as turmas, os quais proporcionavam maior socialização entre os estudantes.

Contudo, em relação aos problemas sentidos nessa etapa de sua formação, a professora aponta para a ausência de bagagem teórica, sentida mais tarde ao ingressar no mercado de trabalho, bem como a ênfase excessiva na formação tecnicista voltada à formação de atletas de elite, predominante no currículo dos cursos de graduação em Educação Física da época.

$\mathrm{Na}$ continuidade de seu percurso formativo, logo após o término da formação inicial, a docente realizou um curso técnico de basquete, e em 1987 concluiu o curso de especialização em Educação Física escolar, ambos em instituição pública. Declara ter entendimento da necessidade de os professores buscarem novos subsídios para a atuação prática, realizando durante sua trajetória diversos cursos de aperfeiçoamento. No entanto, também argumenta que sentiu ausência de auxílio da Secretaria de Educação na sua formação continuada.

No início de seu percurso profissional teve a experiência de ser professora ACT, durante dois anos, enquanto era estudante de graduação. Nessa fase a professora relata que vivenciou um episódio marcante, no qual a diretora da escola onde trabalhava questionava algumas atividades que ela realizava junto aos alunos.

No processo de transição entre as responsabilidades de estudante para as de professora, declara que vivenciou momentos de sobrevivência, devido à insegurança causada pela ausência de prática na realidade escolar durante a formação inicial, bem como pela distância entre seus ideais e a realidade cotidiana das escolas.

Nossa é um baque, quando você vai para a prática a coisa é totalmente diferente, você aprende um monte de receitinhas [...], mas você vai para a prática vem todo aquele problema social que interfere na aula. Isso enquanto você está na graduação, você nem imagina que vai acontecer. Então a gente tem um choque na entrada (Professora C).
Essa professora, por possuir o ensino profissionalizante em Educação Física, conseguiu prestar concurso para efetivação no magistério estadual antes de concluir sua formação inicial. Dessa forma, passou no concurso no último ano do curso de graduação, ingressando no quadro de professores efetivos do Estado em seu primeiro ano de formada. Contudo, como iniciou sua trajetória sem a habilitação de licenciada, nessa época só pôde trabalhar como professora de $1^{\mathrm{a}} \mathrm{a} 4^{\mathrm{a}}$ séries, esperando alguns anos para acessar a função de professora licenciada e atuar de $5^{\mathrm{a}}$ a $8^{\mathrm{a}}$ séries, nível da educação básica de sua preferência. A professora destaca que nesse nível de ensino poderia trabalhar mais diretamente com a prática das modalidades esportivas, conteúdo em que se sentia mais segura, haja vista esse ter sido predominante em sua formação.

Com relação aos primeiros anos de docência, percebe-se que a professora vivenciou mais o sentimento de sobrevivência na escola do que de descoberta da sua profissão. Durante o tempo em que trabalhou na primeira escola como efetiva, a professora lembra, além da questão da distância entre o que ela esperava da sua profissão e a realidade encontrada, das péssimas condições de trabalho oferecidas para desenvolver suas atividades.

A gente trabalhava na graduação, sempre tinha espaço e material, quando eu me efetivei não tinha nada, trabalhei muito tempo sem ter nada [...]. A maior dificuldade foi essa: espaço físico para a prática do esporte (Professora C).

Contudo, relata que, diferentemente do momento atual da sua trajetória, "naquele tempo as crianças queriam brincar e aprender, eles não brigavam muito, eles queriam mesmo era brincar e aprender coisas novas" (Professora C), destacando assim o interesse dos alunos pelas aulas por ela propostas.

De acordo com a transcrição dos assentamentos funcionais e cadastrais, a professora $\mathrm{C}$ teve uma trajetória longa no trabalho administrativo em escolas estaduais e na Secretaria de Educação, dentre eles os cargos de diretora, assistente e secretária, permanecendo aproximadamente 15 anos (1991 a 2006) em cargos de confiança.

A saída da secretaria da escola e o retorno para sala de aula em 2006 ocorreram pelo fato de que "acabou aquela função de que eram os políticos que indicavam esses cargos" (Professora C). O Governo do Estado de Santa Catarina realizou um concurso para efetivação dos especialistas de classe, os quais vieram a assumir as secretarias das escolas dentro da rede estadual. Para tanto, a professora afirma que não prestou o concurso nesse momento, porque 
não pretendia abandonar uma carreira consolidada, desistindo dos anos de serviço que já tinha no magistério estadual, para ganhar um salário inferior ao que recebia como professora de sala de aula.

$\mathrm{Na}$ escola em que essa professora desenvolve suas atividades docentes atualmente, ela trabalhou durante 10 anos, incluindo ali um tempo como secretária e diretora. Após esse período, saiu para trabalhar na secretaria de outra escola, retornando em 2006 para reassumir a função de professora de Educação Física.

No momento em que retornou a sala de aula, pelos anos de intervenção no magistério estadual, a professora já se encontrava em fase de desinvestimento profissional. Todavia, devido ao retorno de contato direto com os alunos após tantos anos, relata que vivenciou alguns sentimentos característicos da fase de entrada na carreira, como o choque com a realidade. Ao retornar à escola, percebeu várias mudanças ocorridas na Educação Física, as quais a levaram a ter alguns problemas com os alunos decorrentes da não aceitação de sua atuação profissional.

$\mathrm{Na}$ ocasião atual, além da vivência de aspectos característicos da fase final do percurso profissional, demonstra vivenciar sentimentos de consolidação na profissão, representados pela constatação do começo da aceitação do seu trabalho pelos alunos. Essa experiência é enfatizada por seus colegas de trabalho, os quais declaram que, ao retornar para a sala de aula, a professora C enfrentou certa resistência dos alunos em relação ao trabalho por ela proposto. Todavia, reconhecem que, atualmente, os alunos estão se adaptando ao trabalho e melhorando seu relacionamento com a docente.

Nós tivemos uns três meses que foram uma guerra $[. .$.$] tivemos alunos revoltadíssimos.$ Eles são revoltados, o que eles não querem, eles não fazem, é um escândalo, mas ela conseguiu (Orientadora educacional C).

No começo quando ela voltou [...] teve uma resistência, mas depois ela foi com jeitinho e hoje eles adoram a aula de Educação Física [...] (Colega do corpo docente C).

No entanto, alguns motivos levam-na a desejar a saída do contexto escolar nesse momento. Dentre eles, destacam-se o sentimento de abandono do ensino por parte do Governo, bem como pelo crescimento da violência nas escolas e, consequentemente falta de segurança no trabalho. Como pode ser visualizado em seu relato: "Eu estou com vontade de ir embora, por causa disso, por causa da falta de segurança que a gente realmente tem na escola, isso a gente sente muito" (Professora C). A diretora de sua escola reconhece que a professora $\mathrm{C}$ sofre no cotidiano escolar com as péssimas condiçôes de trabalho e com o aumento da violência na escola.

No que se refere aos sentimentos predominantes ao fato de afastar-se da docência escolar, a educadora relata que a rotina do dia-a-dia do seu trabalho a leva a aguardar o afastamento de forma serena, sem ansiedade e preocupação. Fato que é comprovado na declaração de seus colegas de trabalho, os quais percebem que a professora está tranquila e espera a aposentadoria sem ansiedade, apesar de reconhecerem que ela se apresenta cansada devido aos anos de docência.

Outros motivos que levam a docente a desejar a aposentadoria se referem ao fato de não poder avançar nos planos de cargos e salários do magistério estadual e a preocupação em torno da mudança da legislação referente à aposentadoria docente, principalmente $o$ aumento do tempo de serviço e da idade, sentimento que é confirmado por sua colega do corpo docente.

O governo está com a tabela toda achatada, a gente parou no tempo, mudou a idade, mudou o tempo de serviço, mas ele não investiu na tabela, não mexeu na tabela dos vencimentos dos professores, nada, continua igualzinha como era quando era assim: só 25 anos de serviço (Professora C).

A aposentadoria docente representa para essa professora o encerramento de uma vida produtiva, um direito concedido por lei, que lhe proporcionará a segurança de ter um salário, podendo assim dedicar-se a outros interesses, porque "[...] aquele salário está lá, é meu, eu tenho direito, eu trabalhei para ele" (Professora C). Nessa perspectiva, tem como metas após a aposentadoria trabalhar com artesanato, aprender a pintar, além de mexer na terra, atividades que segundo ela demandam tempo e tranquilidade.

\section{Professora D: a trajetória docente em Educação Física marcada pelas atividades rítmicas e expressivas}

A trajetória docente da professora D sempre esteve amparada pelas atividades rítmicas e expressivas. A dança, as coreografias e as peças de teatro sempre foram atividades que a encantaram em sua profissão e que a levaram a permanecer no magistério, apesar das muitas frustrações e descontentamentos que vivia no seu cotidiano do trabalho.

A professora relata que as atividades rítmicas e expressivas foram as experiências positivas mais marcantes da sua formação inicial, juntamente com algumas disciplinas cursadas, como a de psicologia, didática e recreação. Por outro lado, destaca alguns 
pontos negativos dessa fase, principalmente a formação tecnicista voltada para a formação de atletas e distante da realidade das escolas. Em seu relato, argumenta que "a faculdade naquela época estava muito preocupada em melhorar o nível técnico de atletas de elite, de olimpíadas, de esporte de alto nível" (Professora D).

$\mathrm{Na}$ continuidade de seu percurso formativo, em 1994, concluiu em uma instituição pública o curso de pós-graduação em nível de especialização em Atividade Física e Saúde. Para ela a formação continuada é importante para reanimar os professores e renovar as atividades desenvolvidas em sala de aula, servindo, sobretudo como complementação de conteúdos que faltaram durante a formação inicial. Nesse sentido, sempre buscou realizar cursos de capacitação que viessem a contribuir com sua atuação profissional, mesmo sentindo falha da Secretaria de Educação na formação continuada dos professores.

Para a orientadora educacional, a docente D está constantemente comprometida com a busca de novos conhecimentos e melhor capacitação, "[...] é uma pessoa que busca um conhecimento mais científico, tenta se capacitar, tenta trazer coisas novas [...] é uma pessoa com muitas ideias [...]. É uma professora que não parece que está se aposentando" (Orientadora educacional D).

A formação mais tecnicista, voltada ao treinamento de alto rendimento e sem muitas experiências no cotidiano escolar durante o curso de graduação, levou a professora a vivenciar intensamente, no processo de transição da formação inicial para o magistério público, uma crise de sobrevivência na profissão.

No começo de seu percurso profissional, trabalhou oito meses como ACT e ao se efetivar no magistério estadual, em 1981, foi trabalhar com turmas de $1^{\text {a }}$ a $4^{\mathrm{a}}$ série, o que para ela "era muito diferente [...] estava completamente insegura e despreparada". Essa experiência de trabalhar com turmas das séries iniciais lhe causou muita insegurança e um forte choque com a realidade. Em sua entrevista declara que "foi uma transição difícil, cheguei a ter um choque, eu queria correr, não corri porque eu tinha que sustentar a família, senão teria corrido. $\mathrm{O}$ sofrimento foi grande" (Professora D).

A professora expõe que teve também muitas dificuldades iniciais causadas pela distância do local de trabalho de sua casa, bem como pela dificuldade de conciliar o trabalho na escola e o cuidado com as filhas recém-nascidas, demonstrando que a vida familiar influenciou fortemente o início de sua carreira no magistério estadual. Além disso, nessa época efetivouse na rede municipal de educação, transitando de uma escola para outra durante seis anos, quando optou por permanecer apenas na rede estadual de educação.
Eu tinha que sair antes das cinco de casa, neste tempo eu passei também no concurso da prefeitura e peguei aula lá na Lagoa da Conceição. Então um dia eu ia para a Lagoa da Conceição e outro dia eu ia para Tijucas, dava aula o dia inteiro, sendo que um dia eu tinha que sair de uma escola e ir para outra, imagina a distância, a correria que era [...] (Professora D).

As dificuldades encontradas na relação com os alunos, no início da docência, estavam ligadas a não aceitação de seu trabalho por parte dos estudantes do sexo masculino. Para ela, esse problema se deu pelo fato de "chegar à escola com a cabeça pronta", com a certeza de que ia trabalhar diferentes modalidades esportivas. Porém, essa opção lhe causou conflitos, pois os alunos não aceitaram e tornaram a relação complicada.

De modo similar, a decepção com a classe docente estava pautada, principalmente, nas dificuldades de relacionamento e trocas de experiência com os pares, os quais provocaram um sentimento de isolamento nesse momento de sua trajetória profissional.

Quando eu comecei [...] eu vi que tinham muitos atritos, discussões, falta de conhecimento, culturas diferentes, que era complicado o relacionamento, o trabalho em conjunto era complicado, muita fofoca e para mim aquilo foi uma decepção e um trauma, eu quis correr por causa disso também. Consequentemente acabava-se trabalhando sozinha, com seu método, seu próprio pensamento, ninguém conseguia dar um direcionamento em conjunto (Professora D).

Apesar disso, um dos aspectos ligados à descoberta da profissão, relatado pela professora, refere-se ao carinho recebido e ao bom relacionamento com alguns alunos, nesse caso ela destaca que os estudantes "[...] são muito carinhosos, gostam de agradar, de beijar, abraçar, vibram, as crianças vibram muito quando você dá uma atividade, eles gostam, principalmente as séries iniciais, tudo o que se propõe para eles é novidade" (Professora D). Nessa etapa, a docente destaca ainda como importante o fato de trabalhar na área de dança, com montagem de coreografias e apresentaçōes.

Em uma fase de consolidação de suas atividades docentes, vinda depois de algum tempo, depois de "tanto sofrer, de tanto ter desentendimento com os alunos", a professora acredita que aprendeu que precisaria partir do conhecimento deles, de suas histórias, do que eles gostam, para então chegar ao seu objetivo.

A fase de consolidação ou estabilização na carreira docente dessa professora realmente demorou a chegar, durante muitos anos ela buscou outras atividades profissionais (academia própria, recreação, 
hidroginástica e natação), bem como a realização de cursos e concursos em outras áreas para conciliar com o magistério até o momento que se sentisse segura para largar a docência. No entanto, declara que depois de muitos anos percebeu que não adiantava fugir, mas buscar a realização profissional dentro da sua área.

Em um momento posterior, destacado como de diversificação no percurso profissional, observouse na transcrição dos assentamentos funcionais e cadastrais que a professora $\mathrm{D}$ foi diretora eleita de sua escola por dois anos (1991 a 1993). Um período que segundo ela foi muito importante, sendo tanto gratificante quanto frustrante. $\mathrm{O}$ lado positivo estava ligado ao fato de mudar conceitos, de ter outras responsabilidades, de entender melhor como é uma escola e como funciona a sua parte administrativa, à qual ela era alheia até aquele momento. No entanto, essa experiência trouxe também alguns episódios negativos, principalmente problemas com o grupo de professores que desejava que fosse outra candidata eleita e que ficou muito tempo "[...] colocando dificuldades, fazendo fofoca [...], foram dois anos bem difíceis, eu envelheci 10 anos naqueles dois anos, porque eu lutei contra a corrente o tempo todo" (Professora D).

$\mathrm{Na}$ fase atual de seu percurso profissional, revela que ainda não conseguiu a aposentadoria devido à mudança na legislação quanto ao aumento do tempo de serviço e da idade. Ressalta-se que, apesar do desejo de abandono da docência em várias fases de sua trajetória, ultimamente a docente demonstra certa serenidade em relação à fase final de sua carreira no magistério público estadual.

Nesse estágio, busca um afastamento progressivo da docência a partir da elaboração de novos objetivos profissionais, bem como da redução da carga horária das aulas e das atividades extraclasse para dedicar-se

\section{Discussão}

\section{Professores de Educação Física: diferentes histórias, semelhantes trajetórias}

Os relatos emitidos pelos professores de Educação Física e seus colegas de trabalho remetem para, além de uma análise individual, uma reflexão conjunta das trajetórias docentes aqui retratadas, as quais revelaram uma gama de características que representam os percursos formativos e profissionais dos professores de Educação Física no magistério público estadual de Santa Catarina. às atividades mais gratificantes. Além disso, o desinvestimento da profissão advém de uma sensação de alívio e descomprometimento, de estar livre para novas escolhas. A orientadora educacional da escola confirma a tendência da docente $\mathrm{C}$ em querer reduzir a carga horária de trabalho para dedicar-se às atividades mais gratificantes.

Na compreensão das três colegas de trabalho entrevistadas, apesar das péssimas condições de trabalho, da falta de organização e iniciativas do grupo de professores, assim como do descontentamento com as políticas educacionais, a professora $C$ não manifesta ansiedade em se aposentar. As colegas percebem que a educadora espera esse momento de forma tranquila e sensata, além de apresentar-se motivada no trabalho por estar na fase final de sua carreira no magistério.

$\mathrm{Na}$ opinião das colegas de trabalho e da própria professora, esse desinvestimento sereno é resultado do envolvimento em atividades teatrais realizadas com alunos no cotidiano escolar, uma atividade gratificante e que traz realização profissional para essa docente.

[...] nossa! Quando ela vai assistir um teatro de rua com essa turma, quando eles montam uma peça, ela sente que foi uma coisa que partiu dela. [...]. Eu vejo que o teatro na vida dela realmente como um escape [...] (Secretária C).

A aposentadoria representa na vida dessa educadora um descanso merecido, uma missão cumprida enquanto docente, no qual ela poderá dar continuidade ao trabalho realizado com teatro por meio de ação comunitária, como um trabalho voluntário, afastado do contexto escolar. Em seu depoimento, evidencia-se que ela pretende continuar "[...] trabalhando com o teatro e não dependendo de investimento público. Trabalhar mais a nível comunitário [...], uma ação comunitária. [...], para mim será um recomeço e isso é bom" (Professora D).

Os percursos formativos dos docentes A e C tiveram início durante a educação básica, no curso profissionalizante em Educação Física. Decisão semelhante foi tomada pelos professores investigados por JungEs (2006) e por ConTI (2003), os quais optaram por realizar o curso de magistério em nível médio, antes de ingressar no curso universitário.

A formação inicial dos professores de Educação Física possibilitou experiências positivas diversificadas, ao mesmo tempo em que ofereceu 
problemas e experiências negativas muito similares, nomeadamente os estágios distantes da realidade, o déficit na relação teoria e prática, além da formação tecnicista voltada à formação de atletas e não condizente com as dificuldades enfrentadas no diaa-dia de escolas públicas.

A literatura consultada comprova que as imagens que alguns professores guardam da sua formação inicial não são muito agradáveis, sendo citadas frequentemente como os aspectos mais problemáticos desse período a carência de preparação pedagógica para o exercício da função docente, bem como a deficiência na comunicação entre a teoria e a prática concreta nas escolas (Almeida \& Fensterseifer, 2007; Bello, 2003; Betti \& Mizukami, 1997; Caldeira, 2000; Conti, 2003; Farias, Folle, Boscatto \& Nascimento, 2007; Gatti, Esposito \& Silva, 1994; Loureiro, 1997; Medeiros, 2004). Para tanto, essa etapa da formação profissional acaba se tornando defasada e desajustada do contexto educacional, além de não preparar os professores para assumirem suas tarefas relativas ao ensino (BELLO, 2003; FloRES, 1999; GONÇALVES, 2000).

Contrariamente a essas evidências, alguns estudos têm apontado que os professores acreditam que suas habilitaçôes realmente possibilitaram aprendizagens necessárias para o enfrentamento do cotidiano de sala de aula, promovendo expectativas realistas de sua profissão e evitando o choque com a realidade (HEBERT \& Worthy, 2001; Monteiro \& Mizukami, 2002).

Por outro lado, o reconhecimento do estágio curricular como um processo artificial, distante da realidade educacional e que não fornece subsídios necessários para a intervenção docente, retratados por três dos professores entrevistados e por outros professores iniciantes participantes das investigações consultadas na literatura (FARIAS et al., 2007; SILVA, 1997), não foi compatível com a experiência narrada pelo professor B. O docente declara que seu estágio, efetivado no cotidiano de escolas públicas carentes, possibilitou-lhe vivências significativas em uma realidade na qual veio atuar durante todo o desenvolvimento de sua carreira no magistério estadual.

De modo similar, os estágios curriculares proporcionaram, aos professores investigados por JUNGES (2006) e por CALDEIRA (2000), muita segurança, tornando-se essenciais em sua formação e demonstrando a grande contradição existente entre um curso de formação e a realidade escolar, bem como o despreparo que possuíam naquele momento para enfrentar a docência.

Outro fato importante narrado pelas professoras $\mathrm{C}$ e $\mathrm{D}$, assim como por uma professora em final de carreira investigada por Almeida e Fensterseifer
(2007), remete à recordação de que seus cursos de graduação foram extremamente tecnicistas e voltados à formação de atletas. Destaca-se que na época em que essas professoras realizaram sua formação inicial, anteriormente à década de 80 , o esporte realmente era visto como um fenômeno de massa, fazendo da Educação Física escolar um espaço para a formação de talentos esportivos brasileiros (KRÜGER, 2007). Para o autor, as críticas realizadas atualmente em relação ao professor de Educação Física escolar têm contribuições importantes daquele período histórico, no qual os professores eram formados com características para se tornarem técnicos esportivos e não para enfrentarem os desafios da realidade educacional brasileira.

A formação continuada, segundo VAlle (2003), faz parte dos projetos de um número significativo de professores que pretende permanecer no magistério, sendo motivada, principalmente pela vontade de criar novas situações de ascensão na carreira e de melhorar sua competência pedagógica. Nesse sentido, além da questão formativa tida como subsídio para a atuação prática, a continuidade dos estudos permitiu aos professores de Educação Física investigados uma ascensão nos planos de cargos e salários da carreira docente no magistério público estadual de Santa Catarina.

As estratégias de formação continuada foram extremamente semelhantes entre os professores de Educação Física, nomeadamente a pós-graduação em nível de especialização e os cursos de capacitação. Para tanto, reconhecem que a continuidade do percurso formativo durante o desenvolvimento da docência é de extrema necessidade. Essa consideração de que a capacitação profissional é intrínseca a qualquer profissão, devendo ser permanente na trajetória docente, para o aprimoramento dos conhecimentos e habilidades profissionais, tem sido constatada por autores de diferentes realidades (BELlo, 2003; MedeIros, 2004; Nono \& MizuKami, 2006; Silva, 1997).

Contudo, o descontentamento com a falta de auxílio da Secretaria de Educação para com a continuação dos percursos formativos ao longo dos anos de docência foi enfatizado por todos os docentes. Realmente, as políticas públicas, apesar de alguns avanços, ainda deixam a desejar no que se refere ao processo da capacitação de professores, o qual muitas vezes é oferecido como uma simples reciclagem, ao contrário de um processo de desenvolvimento profissional contínuo (GONÇALVES \& PASSOS, 2004).

A investigação realizada por GATTI, EsPÓsITo e SILVA (1994), com professores de escolas municipais de educação, revelou resultados diferenciados, na qual a maioria dos cursos de formação continuada 
frequentados pelos docentes era organizada pelas próprias Secretarias Municipais de Educação.

$\mathrm{O}$ ingresso no magistério pressupõe determinado grau de formação, correspondente ao nível de ensino almejado, e aprovação em concurso, tornando-se esses requisitos essenciais à construção de uma carreira profissional (VALLE, 2003). Nesse sentido, evidencia-se que o começo do percurso profissional dos quatro docentes de Educação Física pesquisados foi marcado pela contratação como professores ACTs. Todavia, esses educadores não demoraram muitos anos para ingressar, por meio de concurso público, no quadro de servidores públicos efetivos.

Experiência diferenciada foi verificada por JUNGES (2006), ao investigar a trajetória de vida de quatro professores também em final de carreira, evidenciando que na época de ingresso na docência daqueles educadores, conseguir um emprego na educação por meio de indicação política ou por troca de favores era frequente em órgãos públicos.

O processo de entrada na carreira dos professores de Educação Física revelou a existência simultânea de sentimentos de sobrevivência e de descoberta, sobressaindo-se o primeiro em relação ao segundo. Huberman (2000) lembra que, com frequência, os professores iniciantes vivenciam tanto o aspecto da sobrevivência quanto o aspecto da descoberta. No entanto, para o autor é a descoberta da profissão que permite suportar as experiências de sobrevivência.

O choque com a realidade, aspecto predominante nas narrativas das experiências dos professores investigados, traduz o grande impacto por eles sofrido quando ingressaram na profissão (JESUS \& Santos, 2004; Silva, 1997). Além disso, destaca-se que os sentimentos que caracterizam a sobrevivência na profissão são mais frequentemente citados, como experienciados no ingresso profissional do que os da descoberta, tanto por professores nacionais (Almeida \& Fensterseifer, 2007; Larocca \& Junges, 2004; Monteiro \& Mizukami, 2002; Pizzo, 2004; Shigunov, Farias \& Nascimento, 2002) quanto internacionais (ANDERSON \& OLSEN, 2006; Caldeira, 2000; Cavaco, 1990; Flores, 2006; Fontoura, 2000; WeIss, 1999). Por outro lado, poucos pesquisadores referenciam que os professores por eles investigados apontam mais indícios fáceis do que conturbados, manifestando a sensação de encontrar poucas dificuldades nesse período (Bragança, 2004; Hebert \& Worth, 2001; Hopf \& CANField, 2001; Veiga et al., 2007).

A fase inicial do percurso profissional desemboca em um estágio de comprometimento definitivo, de consolidação ou estabilização. Essa nova etapa trata-se, além de um ato administrativo (nomeação oficial), de uma escolha subjetiva, do comprometerse definitivamente com a profissão (BELlo, 2003; Huberman, 2000; Jesus \& Santos, 2004). Evidencia-se que o ato administrativo ocorreu no início da carreira de todos os professores investigados, porém a escolha subjetiva, o comprometimento definitivo com a docência pela professora $\mathrm{D}$ demorou em se consolidar, haja vista ela tenha tentado de diversas formas encontrar outra atividade profissional que lhe possibilitasse sustentação financeira e, consequentemente, abandono do ensino.

Experiência diferenciada foi apresentada por FONTOURA (2000), o qual verificou que os professores portugueses investigados foram obrigados a uma longa espera para conseguir que o ato administrativo sancionasse os resultados de suas formaçóes e a escolha subjetiva que haviam concretizado.

Os percursos profissionais de todos os docentes investigados no presente estudo foram marcados por experiências em cargos administrativos, bem como pela realização de outras atividades profissionais paralelas ao magistério público estadual, sejam elas em diferentes áreas da Educação Física ou em outras redes de ensino. A experiência de exercer outras funções no ambiente escolar durante a trajetória docente também foi vivenciada pelos docentes pesquisados por LOUREIro (1997), Moita (2000), Hopf e Canfield (2001) e Linhares (2006). Para tanto, Larocca e Junges (2004) revelam que o exercício de outras atividades ou funções, além da docência, realmente configura-se como um fator constituinte do profissional docente.

Os cargos comissionados e de confiança ocupados pelos professores de Educação Física ocorreram em uma fase de diversificação profissional, na qual todos os educadores assumiram o cargo de diretor, e uma professora ainda foi admitida como secretária e assistente. Os professores no desenvolvimento de suas carreiras costumam, em um estágio de diversificação, lançar-se a novas experiências pessoais e a novas atividades no contexto educacional. Além disso, entram em uma fase de renovação, experimentando novas ideias e buscando assumir cargos administrativos (HUBERMAN, 2000; LOUREIRO, 1997; NASCIMENTO \& GRAÇA, 1998).

Os últimos anos de exercício da docência, mais do que em qualquer outra profissão, surgem como um desafio em que uma etapa está sendo concluída, resultando em uma avaliação da capacidade de desvinculação das responsabilidades e do ambiente no qual as atividades até então são desenvolvidas (Hopf, 2002). 
$\mathrm{Na}$ fase final de suas carreiras no magistério público estadual, pode-se constatar que os professores apresentam certo ressentimento, causado principalmente pelo descontentamento com as políticas educacionais, com o aumento da violência nas escolas e do desinteresse dos alunos pelas aulas de Educação Física, bem como as péssimas condições de trabalho oferecidas nas escolas. De modo similar, os professores participantes dos estudos de Junges (2006) e de CALDAS (2007) destacam como principais obstáculos da docência: a desvalorização, as más condições de trabalho nas escolas, os baixos salários, o número reduzido de profissionais nas equipes pedagógicas, as relações estabelecidas e a violência no ambiente de trabalho.

No final do percurso profissional dos professores de Educação Física, apesar de todos demonstrarem alguns resquícios ligados tanto a um desinvestimento amargo quanto a um desinvestimento sereno, apenas para o professor A predomina a sensação maior de desinvestimento amargo, enquanto os demais esperam a aposentaria de forma mais serena. Todavia, constata-se uma preocupação geral dos professores com as mudanças frequentes na legislação referente à aposentadoria docente.

Investigações realizadas com docentes da educação superior (BRAGANÇA, 2004; CHINELLI \& JUNQUEIRA, 1998; Ferreira \& KrUG, 2001; Hopf, 2002; Hopf \& CANFIELD, 2001; VeIGA et al., 2007) revelaram resultados diferenciados dos encontrados nessa investigação e em demais pesquisas concretizadas com professores em final de carreira na educação básica (BELLO, 2003; Chinelli \& Junqueira, 1998; Farias et al., 2007; Shigunov, Farias \& Nascimento, 2002). Os docentes universitários normalmente não demonstram entrar numa fase de desinvestimento profissional, e com a chegada da aposentadoria buscam formas de permanecer exercendo suas funções docentes no âmbito de instituições de ensino superior.

O sentimento de um final de carreira amargo, no percurso profissional de apenas um professor investigado, também foi evidenciado por LOUREIRO (1997), por Hopf e CANField (2001) e por Veiga et al. (2007), os quais deixaram transparecer um tom entristecido diante das indagações e um sentimento de amargura quanto à docência. $\mathrm{O}$ ressentimento e o descontentamento que os professores demonstram no final de seus percursos profissionais refletem a indicação de VALLE (2003), de que, muitas vezes, esses docentes são marcados pelo desencantamento diante de um percurso profissional que prometeu muito, mas permitiu pouco em nível de pretensões tanto pessoais quanto profissionais.

A sensação expressa na fase final da trajetória docente do professor A remete à definição de CHINELLI e JunQueIRA (1998, p. 46), “[...] enquanto para alguns a aposentadoria significa 'crise', para outros representa a 'liberdade' ou a 'crise' que conduz à 'liberdade”". Por outro lado, enquanto para o professor B a aposentadoria não representa nada, pois não lhe garante condições financeiras adequadas, para as duas professoras ela representa um direito concedido por lei, o encerramento de uma vida produtiva ou um descanso merecido.

BRAGANÇA (2004) corrobora essas informações, declarando que muitos professores atribuem significados à aposentadoria ligados a um direito conquistado por meio da conclusão do ciclo produtivo, a uma recompensa justa pelos anos de trabalho, a uma garantia de segurança financeira e a um descanso. Além disso, para as mulheres, a aposentadoria, também, representa uma desobrigação de cumprir horários e prazos, um tempo isento em dar satisfaçóes e que oferece maior disponibilidade para realizar o que gostariam. Contrariamente, os professores investigados por Ferreira e KrUg (2001) declararam que continuam demonstrando interesse e entusiasmo pelo ensino, e a aposentadoria, que poderia representar um "desencanto", surge como um desafio, o início de uma nova fase em suas carreiras profissionais.

Nessa perspectiva, as trajetórias docentes relatadas e as expectativas de reinserção no mercado de trabalho após a aposentadoria evidenciam que os educadores investigados não apresentam indícios de passar à fase de emérito do ciclo de vida docente proposta por STEFY et al. (2000), a qual se caracteriza pelo retorno às atividades docentes após a aposentadoria. Os casos que mais se aproximam da permanência nas atividades já realizadas e ligadas à Educação Física, porém fora do contexto escolar, são os interesses do professor B em continuar como supervisor de arbitragem e da professora D em dar continuidade ao trabalho realizado com teatro em ações comunitárias. De modo contrário as expectativas dos professores de Educação Física investigados, os docentes entrevistados por LAROCCA e Junges (2004) e por JUNGES (2006), mesmo chegando ao final de suas carreiras, parecem não se inserirem na fase de desinvestimento na profissão, possuindo planos futuros na carreira docente. 


\section{Conclusão}

Diante das limitações de investigaçôes conduzidas com amostras pequenas, as trajetórias docentes retratadas no presente estudo demonstraram como os professores investigados de Educação Física da cidade de Florianópolis (SC) analisam suas experiências formativas e profissionais vivenciadas ao longo dos anos de docência no magistério público estadual.

A formação inicial desses docentes, ao mesmo tempo em que oportunizou experiências positivas diversificadas, possibilitou vivências negativas muito similares, destacando-se a distância entre suas experiências formativas e a realidade das escolas públicas. A continuidade do percurso formativo foi concretizada por meio de cursos de pós-graduação em nível de especialização, bem como por meio de cursos de capacitação profissional, apesar da falta de auxílio junto à Secretaria de Educação.

A entrada na carreira docente possibilitou sentimentos tanto de sobrevivência quanto de descoberta, sobressaindo-se naquele momento o choque com a realidade. Além disso, no decorrer de seus percursos profissionais, os professores de Educação Física assumiram tanto cargos comissionados quanto cargos de confiança.

O desinvestimento amargo predomina no percurso profissional de apenas um professor, enquanto os demais demonstram aguardar a aposentadoria de forma mais serena. Nesse sentido, após a aposentadoria pretendem desenvolver atividades profissionais diversificadas, não retornando à docência no ambiente escolar.

As evidências encontradas apontam que, mesmo encontrando um início de vida profissional diferente de suas expectativas e vivenciando algumas frustrações ao longo dos anos de docência, os professores buscaram, a partir de atividades que lhe proporcionassem prazer e realização profissional, superá-las e permanecer na profissão escolhida até o final de seus percursos profissionais.

Os resultados encontrados, quando comparados à literatura consultada, permitem a sugestão de um aprofundamento na análise que os professores da educação básica e superior fazem de suas trajetórias docentes e as estratégias que utilizam para superar as dificuldades e as barreiras encontradas em cada fase de seus percursos profissionais, revelando a influência que elas exercem na relação que os docentes estabelecem com a sua profissão no momento de se afastarem da docência. Além disso, futuras investigações podem contribuir com propostas para a formação tanto inicial quanto continuada dos professores, bem como para minimizar as dificuldades encontradas por professores iniciantes e os descontentamos dos docentes em relação às políticas educacionais, as más condiçōes de trabalho e a violência nas escolas.

\section{Abstract}

Teacher's trajectory in physical education: formative and professional routes

This study aimed to analyze the professional trajectory of Physical Education (PE) teachers. The formative and professional routes of four PE teachers, with more than twenty-five years of professional activity in state schools in the city of Florianopolis were investigated. To analyze the teaching trajectory it was used three sources of information: a) semi-structured interviews with the PE teachers; b) semi-structured interviews with three workmates; c) documental analysis. The technique of content analysis was used for information analysis. The results revealed that the teachers, by the same time they had different positive experiences during their initial training, they had very similar negative experiences, emphasizing the distance between University's experiences and the reality of public schools. As a strategy to continue in the formative course, teachers made post-graduation courses, for expertise and professional improvement. The start in the career made possible feelings of survive and discovery, emphasizing the contrast to the reality. During professional journey, they received activities of reliance at schools they worked. The hard disinvestment predominates in the professional journey of only one teacher, but the other demonstrated to wait for retirement in a soft way. Concerning expectations related to the retirement, they intend to develop different professional activities, but not returning to teaching activities.

\section{UnITERMS: Professional formation; Career start; Teacher life cycles; Retirement.}




\section{Nota}

Alexandra Folle é bolsista CAPES.

\section{Referências}

ALMEIDA, L.; FENSTERSEIFER, P.E. Professoras de educação física: duas histórias, um só destino. Movimento, Porto Alegre, v.13, n.2, p.13-35, 2007.

ALVES-MAZZOTTI, A.J.; GEWANDSZNAJDER, F. O método nas ciências naturais e sociais: pesquisa qualitativa e quantitativa. 2. ed. São Paulo: Pioneira, 1998.

ANDERSON, L.; OLSEN, B. Investigating early career urban teachers' perspectives on and experiences in professional development. Journal of Teacher Education, Washington, v.57, n.4, p.359-77, 2006.

BARDIN, L. Análise de conteúdo. Rio de Janeiro: Ediçōes 70, 1977.

BARONE, T.; BERLINER, D.C.; BLANCHARD, J.; CASANOVA, U.; McGOWAN, T. A future for teacher education: developing a strong sense of profissionalism. In: SIKULA, J.; BUTTEY, T, J.; GUYTON, E. (Orgs.) Handbook of research on teacher education. New York: MacMillan, 1996. p.1118-49.

BELLO, I.M. Contribuições das histórias de vida profissional na formação de professores: limites e possibilidades. Cadernos de Educação, Pelotas, v.7, n.1, p.77-92, 2003.

BEN-PERETZ, M. Episódios do passado evocados por professores aposentados. In: NÓVOA, A. (Org.) Vidas de professores. 2. ed. Porto: Porto, 2000. p.201-14.

BETTI, I.C.R.; MIZUKAMI, M.G.N. História de vida: trajetória de uma professora de educação física. Motriz, Rio Claro, v.3, n.2, p.108-15, 1997.

BOGDAN, R.; BIKLEN, A. Investigação qualitativa em educação: uma introdução à teoria e aos métodos. Porto: Porto, 1994. BRAGANÇA, A.B.S. Aposentadoria: a experiência de professores aposentados do instituto de biologia da UNICAMP. 2004. 102 f. Dissertação (Mestrado em Gerontologia) - Faculdade de Educação, Universidade Estadual de Campinas, Campinas, 2004. BURKE, P.J.; CHRISTENSEN, J.C.; FESSLER, R.; McDONNELL, J.H.; PRICE, J.R. The teacher career cycle: model development and research report. In: ANNUAL MEETING OF THE AMERICAN EDUCATIONAL RESEARCH ASSOCIATION, 1987, Washington. Proceedings... Washington: AERA, 1987. p.1-59.

CALDAS, A.R. Desistência e resistência no trabalho docente: um estudo das professoras e professores do ensino fundamental da rede municipal de educação de Curitiba. 2007. 164 f. Tese (Doutorado em Educação) - Universidade Federal do Paraná, Curitiba, 2007.

CALDEIRA, A.M.S. Fragmentos da história de vida de uma professora: em busca de traços e processos constitutivos de sua identidade docente. Educação em Revista, Belo Horizonte, n.32, p.103-22, 2000.

CAVACO, M.H. Retrato do professor enquanto jovem. Revista Crítica de Ciências Sociais, Coimbra, v.29, p.121-39, 1990. CHINELLI, F.; JUNQUEIRA, C. Aposentadoria docente, crise de identidade e reinserção no mercado de trabalho. Contemporaneidade e Educação, Salvador, v.3, n.4, p.22-60, 1998.

CONTI, C.L.A. Imagens da profissão docente: um estudo sobre professoras primárias em início de carreira. 2003.177 f. Tese (Doutorado em Educação) - Faculdade de Educação, Universidade Estadual de Campinas, Campinas, 2003.

FARIAS, G.O.; FOLLE, A.; BOSCATTO, J.D.; NASCIMENTO, J.V. Carreira docente em educação física: perspectivas na formação inicial, expectativas e valores. In: CONGRESSO NACIONAL DE EDUCAÇÃO, 7., 2007, Curitiba. Anais... Curitiba: Champagnat, 2007. p.853-67.

FEIMAN-NEMSER, S. Staff development and learning to teach. In: ANNUAL MEETING OF THE EASTERN EDUCATIONAL RESEARCH ASSOCIATION, 1982. Detroit. Proceedings... Detroit: AERA, 1982. p.1-18.

FERREIRA, L.M.; KRUG, H.N. Os bons professores formadores de profissionais de educação física: características pessoais, histórias de vida e práticas pedagógicas. Kinesis, Santa Maria, n. 24, p. 73-96, 2001.

FLORES, M.A. (Des)ilusão e paradoxos: a entrada na carreira na perspectiva dos professores neófitos. Revista Portuguesa de Educação, Braga, v.12, n.1, p.171-204, 1999.

. Being a novice teacher in two different settings: struggles, continuities, and discontinuities. Teachers College Record, New York, v.108 n.10, p.2021-52, 2006.

FONTOURA, M.M. Fico ou vou-me embora? In: NÓVOA, A. (Org.) Vidas de professores. 2. ed. Porto: Porto, 2000. p. 171-97. 
GATTI, B.A.; ESPOSITO, Y.L.; SILVA, R.N. Características de professores(as) de $1^{\circ}$ grau no Brasil: perfil e expectativas. Educação \& Sociedade, Campinas, n.48, p.248-60, 1994.

GIL, A.C. Como elaborar projetos de pesquisa. 4. ed. São Paulo: Atlas, 2002.

GONÇALVES, J.A.M. A carreira das professoras do ensino primário. In: NÓVOA, A. (Org.). Vidas de professores. 2. ed. Porto: Porto, 2000. p.141-70.

GONÇALVES, L.R.; PASSOS, S.R.M.M.S. Processo de desenvolvimento profissional do professor: educação continuada. Paradoxa, Niterói, v.10, n.17, p.45-56, 2004.

HEBERT, E.; WORTHY, T. Does the first year of teaching have to be a bad one? A case study of success. Teaching and Teacher Education, New York, v.17, n.8, p.897-911, 2001.

HOPF, A.C.O. Fico ou vou-me embora? Os sentimentos expressos por professores diante da aposentadoria. Revista da Educação Física/UEM, Maringá, v.13, n.2, p.89-96, 2002.

HOPF, A.C.O.; CANFIELD, M.S. Profissão docente: estudo da trajetória de professores universitários de educação física. Kinesis, Santa Maria, n.24, p.49-71, 2001.

HUBERMAN, M. O ciclo de vida profissional dos professores. In: NÓVOA, A. (Org.). Vidas de professores. 2. ed. Porto: Porto, 2000. p.31-62.

JUNGES, K.S. Trajetória de vida, constituição profissional e autonomia de professores. União da Vitória: FACE, 2006. JESUS, S.N.; SANTOS, J.C.V. Desenvolvimento profissional e motivação dos professores. Educação, Porto Alegre, v.52, n.1, p.39-58, 2004.

KRÜGER, L.G. As concepçóes da formação profissional da licenciatura em educação física: trajetórias docentes e suas perspectivas. 2007. 145 f. Dissertação (Mestrado em Educação) - Centro de Educação, Universidade Federal de Santa Maria, Santa Maria, 2007.

LAROCCA, P.; JUNGES, K.S. A constituição do professor no exercício da profissão. Intermeio, Campo Grande, v.10, n. 20, p.42-61, 2004.

LINHARES, E.V. Marcas da memória traduzidas na identidade docente: relatos de vida de professoras alfabetizadoras. 2006. 165 f. Dissertação (Mestrado em Educação) - Centro de Educação de Ciências Humanas e da Comunicação, Universidade do Vale do Itajaí, Itajaí, 2006.

LOUREIRO, M.I. O desenvolvimento da carreira dos professores. In: ESTRELA, M.T. (Org.). Viver e construir a profissão docente. Porto, Porto, 1997. p.119-59.

MEDEIROS, R.N. Professores-profissionais e profissionais-professores a construção de um professor. Linhas, Florianópolis, v.5, n.2, p.253-272, 2004.

MOITA, M.C. Percursos de formação e de trans-formação. In: NÓVOA, A. (Org.). Vidas de professores. 2. ed. Porto: Porto, 2000. p.114-40.

MOLINA NETO, V.; TRIVINOS, A.N.S. A pesquisa qualitativa na educação física: alternativas metodológicas. Porto Alegre: Sulina, 1999.

MONTEIRO, F.M.A.; MIZUKAMI, M.G.N. Professoras das séries iniciais do ensino fundamental: percursos e processos de formação. In: MIZUKAMI, M.G.N.; REALI, A.M.M.R. (Orgs.). Formação de professores, práticas pedagógicas e escola. São Carlos: EdUFSCar, 2002. p.175-201.

NASCIMENTO, J.V.; GRAÇA, A. A evolução da percepção de competência profissional de professores de Educação Física a longo da carreira docente. In: CONGRESSO DE EDUCAÇÃO FÍSICA E CIÊNCIAS DO DESPORTO DOS PAÍSES DE LÍNGUA PORTUGUESA, 6., 1998, La Coruña. Actas... La Coruña: INEF Galícia, 1998. p.320-35.

NONO, M.A.; MIZUKAMI, M.G.N. Processos de formação de professoras iniciantes. Revista Brasileira de Estudos Pedagógicos, Brasília, v.87, n.217, p.382-400, 2006.

PIZZO, S.V. O início da docência e a trajetória profissional segundo a visão de professoras em final de carreira. 2004. 106 f. Dissertação (Mestrado em Educação) - Centro de Educação e Ciências Humanas, Universidade Federal de São Carlos, São Carlos, 2004.

QUEIROZ, M.I. P. Relatos orais: do “indizível” ao “dizível”. In: SIMSON, O.M.V. (Org.). Experimentos com histórias de vida (Itália-Brasil). São Paulo: Vértice, 1988. p.14-43.

RODRÍGUES, L. Da prática a teoria: uma experiência em educação básica. 1987. 337 f. Tese (Doutorado em Educação) Unisersidad Faculdad de Ciências de la Educación, Universidad Autônoma de Barcelona, Barcelona, 1987.

SHIGUNOV, V.; FARIAS, G.O.; NASCIMENTO, J.V. O percurso profissional dos professores de Educação Física nas escolas. In: SHIGUNOV, V.; SHIGUNOV NETO, A. (Orgs.). Educação física: conhecimento teórico x prática pedagógica. Porto Alegre: Mediação, 2002. p.103-52. 
SILVA, M.C.M. O primeiro ano de docência: o choque com a realidade. In: ESTRELA, M.T. (Org.). Viver e construir a profissão docente. Porto, Porto, 1997. p.53-80.

STEFY, B.E.; WOLFE, M.P.; PASCH, S.H.; ENZ, B.J. The model and its application. In: STEFY, B.E.; WOLFE, M.P.; PASCH, S.H.; ENZ, B.J. (Eds.). Life cycle of the career teacher. California: Kappa Delta Pi, 2000. p.1-25.

STROOT, S. Organizational socialization: factors impacting beginning teachers. In: SILVERMAN, S.J.; ENNIS, C. (Orgs.). Student learning in physical education. Champaign: Human Kinetics, 1996. p.339-65.

TRIVIÑOS, A.N.S. Introdução à pesquisa em ciências sociais: a pesquisa qualitativa em educação. São Paulo: Atlas, 1987. VALLE, I.R. A era da profissionalização: formação e socialização profissional do corpo docente de $1^{\mathrm{a}}$ a $4^{\mathrm{a}}$ série. Florianópolis: Cidade Futura, 2003.

VEIGA, I.P.A.; MOREIRA, A.M.A.; SOUZA, J.V.; BORGES, L.F.F.; RESENDE, L.M.G.; PINHEIRO, M.E. Docentes universitários aposentados: ativos ou inativos? Araraquara: Junquira \& Marin, 2007.

WEISS, E.M. Perceived workplace conditions and first-year teachers' morale, career choice commitment, and planned retention: a secondary analysis. Teaching and Teacher Education, New York, v.15, n.8, p.861-79, 1999.

YIN, R.K. Case study research: design and methods. 2nd. ed. London: SAGE, 1995.

\begin{tabular}{|c|c|}
\hline $\begin{array}{r}\text { ENDEREÇO } \\
\text { Alexandra Folle } \\
\text { Av. José Victor da Rosa, } 722 \text { - Bloco A - apto. } 105 \\
\text { 88117-405 - São José - SC - BRASIL } \\
\text { e-mail: afolle_12@hotmail.com }\end{array}$ & $\begin{array}{l}\text { Recebido para publicação: 25/03/2009 } \\
\text { Revisado em: 07/06/2010 } \\
\text { Aceito: 14/06/2010 }\end{array}$ \\
\hline
\end{tabular}

